Original Research Article

\title{
Assessment of knowledge, attitude and practice about dengue in factory workers of Jammu region, India
}

\author{
Roshi $^{1 *}$, Sachin Sharma ${ }^{2}$, Vishal R. Tandon ${ }^{1}$, Brij Mohan Gupta ${ }^{1}$
}

${ }^{1}$ Department of Pharmacology, Government Medical College, Jammu, Jammu and Kashmir, India

${ }^{2} \mathrm{AEO}$, Directorate of Industries and Commerce Jammu, Jammu and Kashmir, India

Received: 06 May 2019

Accepted: 05 June 2019

*Correspondence to:
Dr. Roshi,
Email: roshigupta1986@
gmail.com

Copyright: (C) the author(s), publisher and licensee Medip Academy. This is an openaccess article distributed under the terms of the Creative Commons Attribution NonCommercial License, which permits unrestricted noncommercial use, distribution, and reproduction in any medium, provided the original work is properly cited.

\begin{abstract}
Background: Dengue, a mosquito borne, arboviral disease has become a major cause of health concern in the recent times throughout the world. In India, we have been witnessing annual outbreaks for the past few years and lack of knowledge about prevention and treatment of dengue among majority of the population leads to increased mortality. In spite of this fact, very few studies have been done to know about the knowledge of people regarding dengue fever and whether proper preventive measures are being practiced by the community to limit its spread. The objective of the study is to assess the knowledge, attitude and practices (KAP) regarding dengue in factory workers in Jammu.

Methods: An observational study was conducted in a factory of Jammu to assess knowledge, attitude and practices of factory workers about dengue.

Results: Majority of workers had knowledge about dengue $(92.56 \%)$, source $(81.81 \%)$, nature of disease, symptoms, but complications were not known. Majority of the workers had no idea that laboratory test for dengue is not available in every laboratory. $63.63 \%$ of the workers knew that papaya is useful in dengue. $74.38 \%$ of the workers knew that low platelet count is found in dengue. There were $82.64 \%$ of the workers told that they think dengue is curable and preventable. There were $54.54 \%$ of the workers told that dengue can be prevented by avoiding stagnation of water. $57.85 \%$ of the workers told that they are aware about the sprays used by govt. to kill mosquito.
\end{abstract}

Conclusions: There is a need to bring awareness about dengue, prevention and treatment as it is a prevalent disease now.

Keywords: Dengue, Factory workers, Knowledge attitude practice

\section{INTRODUCTION}

Dengue fever is an arboviral disease which is caused by Aedes mosquito. Dengue virus has four serotypes DEN(IIV). It belongs to the genus Flaviviridae, It is an emerging disease and has become a global health concern. ${ }^{1,2}$ The epidemiology of dengue in India was first reported in Madras (now Chennai) in 1780, and the first outbreak occurred in Calcutta (now Kolkata) in 1963; subsequent outbreaks have been reported in different parts of India., Dengue has seen a 30-fold upsurge worldwide between 1960 and 2010, due to increased population growth rate, global warming, unplanned urbanization, inefficient mosquito control, frequent air travel, and lack of health care facilities. ${ }^{5-7}$ Annual outbreaks are common in India with peak incidence in September to November. Number of dengue cases in India were 188,401 as per National Vector Borne Disease Control Programme. ${ }^{8}$ There is no definitive treatment or vaccine for dengue. Dengue virus infection exhibit varied clinical presentation; hence, accurate diagnosis is difficult and relies on laboratory confirmation. The condition is usually self-limiting and antiviral therapy is not currently available. Supportive care with analgesics, hydration with fluid replacement, and sufficient bed rest forms the preferred management strategy. So, there is a need to control vectors by Vector 
Control Programme and limit its spread to the newer areas. ${ }^{9}$ Dengue virus infection presents with a diverse clinical picture that ranges from asymptomatic illness to DF to the severe illness of dengue haemorrhagic fever/dengue shock syndrome (DHF/DSS). ${ }^{10}$ Various complications associated with dengue are haemorrhage, shock, septicaemia, multiorgan failure and finally death. Therefore, active community participation by organizing frequent health education programmes which aims at improving the knowledge about dengue, attitude towards dengue. The disease and preventive practice to limit its 8read is the need of the hour. It is also important to have a sound knowledge about the correct treatment practice undertaken for dengue to prevent its complications. Review of literature revealed many studies about knowledge, attitude and practices about dengue in different populations. The present study was conducted among factory workers in a factory at Jammu region.

\section{METHODS}

With the permission from Institutional Ethics Committee, Govt. Medical College, Jammu and Directorate of Industries and Commerce, Jammu, an observational study was conducted among factory workers of a factory located in Jammu. A pre-validated questionnaire was circulated among factory workers which was typed in vernacular language (Hindi). This process was done in one day. They were given a time frame of 1 hour to fill the questionnaire. Written informed consent was taken and the workers were informed about the nature and purpose of study. The data was collected and analysed. All the workers of a factory were included after taking consent.

A questionnaire was made regarding knowledge, attitude and practices about dengue in the vernacular language. A person was nominated by Directorate of Industries and Commerce, Jammu from their department who accompanied us to the factory. Filled forms were assessed and the data was expressed in percentage.

\section{RESULTS}

Majority of workers had heard about dengue (92.56\%). Majority of the workers knew that dengue is caused by bite of mosquito $(81.81 \%)$, some told that it is by bite of housefly and other routes like food, air. Majority of the workers knew that dengue mosquito bites during day $(41.32 \%)$. Others told that it bites both during day and night. Majority of the workers had an idea that dengue is more prevalent during rainy season $(55.37 \%)$ followed by summers and winters. Most of the workers had knowledge that mosquito breed in standing water $(82.64 \%)$. Majority of the workers told that dengue has fever followed by body aches, nausea and vomiting. Majority of the workers had no idea that laboratory test for dengue is not available in every laboratory. $63.63 \%$ of the workers knew that papaya is useful in dengue followed by kiwi and other fruits. $74.38 \%$ of the workers knew that low platelet count is found in dengue. Only few workers knew about other complications (Table 1).

Table 1: Knowledge related to dengue.

\begin{tabular}{|lll|}
\hline Knowledge & Number & Percentage \\
\hline Have you ever heard about dengue & 112 & 92.56 \\
\hline Yes & 9 & 7.43 \\
\hline No & 99 & \\
\hline Cause of Dengue & 8 & 61.81 \\
\hline Bite of mosquito & 3 & 6.61 \\
\hline Bite of housefly & 7 & 2.47 \\
\hline No idea & 4 & 5.78 \\
\hline Food and water & & 3.3 \\
\hline Air borne & 50 & \\
\hline Time of biting of dengue causing mosquito & 34 & 28.32 \\
\hline Day time & 16 & 13.22 \\
\hline Night-time & 21 & 17.35 \\
\hline Both day and night & & \\
\hline No idea & 23 & 19 \\
\hline When is dengue more prevalent & 67 & 55.37 \\
\hline Summers & 10 & 8.26 \\
\hline Rainy season & 5 & 4.13 \\
\hline Autumn & 16 & 13.22 \\
\hline Winters & & \\
\hline No idea & 14 & 11.57 \\
\hline Dengue can be transmitted by & & \\
\hline Human to human contact & & \\
\hline
\end{tabular}


Knowledge

Number

Percentage

Blood transfusion

Sharing of food/ clothes with the patient

60

49.58

None of the above

No idea

34

28.09

No idea

7

6

5.78

Common breeding place for mosquito

Burrows and pits

Standing water

0

Plants

100

Garbage

0

82.64

No idea

21

Signs and symptoms of dengue

\begin{tabular}{lll} 
High fever & 80 & 66.11 \\
Severe body aches & 20 & 16.52 \\
\hline Nausea and vomiting & 2 & 1.65 \\
\hline Red spots on the body & 2 & 1.65 \\
\hline Diarrhoea & 6 & 4.95 \\
\hline Pain abdomen & 8 & 6.61 \\
All of the above & 3 & 2.47 \\
No idea & 0 & 0
\end{tabular}

Is the facility of testing for dengue available at each and every laboratory?

\begin{tabular}{|c|c|c|}
\hline Yes & 50 & 41.32 \\
\hline No & 70 & 57.85 \\
\hline Don't know & 1 & 0.82 \\
\hline Consumption of which fruit is most beneficial in a patient of dengue & 77 & \\
\hline Papaya & 2 & 63.63 \\
\hline Mango & 28 & 1.65 \\
\hline Kiwi & 10 & 23.14 \\
\hline Apple & 2 & 8.26 \\
\hline Banana & 2 & 1.65 \\
\hline All & & 1.65 \\
\hline Complications of dengue fever dengue haemorrhagic fever & $\mathbf{0}$ & $\mathbf{0}$ \\
\hline Shock & 12 & 9.91 \\
\hline Low platelet count & 90 & 74.38 \\
\hline Dehydration & 10 & 8.26 \\
\hline Death & 8 & 6.61 \\
\hline Don't know & 1 & 0.82 \\
\hline
\end{tabular}

Table 2: Attitude related to dengue.

\begin{tabular}{|lll|}
\hline Attitude & Number & Percentage \\
\hline Do you feel you are at risk of getting dengue? & 50 & 41.32 \\
\hline Yes & 71 & 58.67 \\
\hline No & 100 & 82.64 \\
\hline Do you think dengue fever is treatable? & 20 & 16.52 \\
\hline Yes & 1 & 0.82 \\
\hline No & & 5.78 \\
\hline No idea & 7 & 85.95 \\
\hline Have you ever tried home remedy for treating dengue at home? & 82.64 \\
\hline Yes & 104 & 8.26 \\
\hline No & & 9.09 \\
\hline Is it possible to prevent dengue? & 100 & \\
\hline Yes & 10 & 11 \\
\hline No & & \\
\hline No idea & 11 & \\
\hline
\end{tabular}


There were $58.67 \%$ of the workers told that they think they have a risk of getting dengue, $82.64 \%$ of the workers told that they think dengue is curable and preventable (Table 2).

There were $54.54 \%$ of the workers told that dengue can be prevented by avoiding stagnation of water, followed by wearing full sleeves $(8.26 \%)$, use of nets and windows
$(8.26 \%)$ and other means. There were $57.85 \%$ of the workers told that they are aware about the sprays used by govt. to kill mosquito. $91.73 \%$ of the workers had not attended any camps or lectures related to dengue. $44.62 \%$ of the workers told that clean water filled containers around their home every six months, $41.32 \%$ of the workers told that that they clean it every month (Table 3 ).

Table 3: Practice related to dengue.

\begin{tabular}{|lll|}
\hline Practice & Number & Percentage \\
\hline How can dengue be prevented? & \multicolumn{1}{|c|}{} \\
\hline Using mosquito sprays and repellants & 10 & 8.26 \\
\hline Wearing full sleeves clothes & 9 & 8.26 \\
\hline Use of window nets, doors & 9 & 7.43 \\
\hline Preventing garbage collection & 8 & 7.43 \\
\hline Regular cleaning of floors & 9 & 6.61 \\
\hline Prevent standing water & 66 & 7.43 \\
\hline All of the above & 0 & 54.54 \\
\hline No idea & 70 & 0 \\
\hline Are you aware that govt. sprays insecticides to control mosquito? & \\
\hline Yes & 51 & 57.85 \\
\hline No & 0 & 42.14 \\
\hline How often do you clean water filled containers around home and office? & 0 \\
\hline Every day & 5 & 4.13 \\
\hline Every alternate day & 4 & 3.3 \\
\hline Every week & 8 & 6.61 \\
\hline Every fortnight & 50 & 41.32 \\
\hline Every month & 54 & 44.62 \\
\hline Every six month & & 8.26 \\
\hline Have you ever attended dengue related camps or lectures? & 10 & 91.73 \\
\hline Yes & 111 & \\
\hline No & & \\
\hline
\end{tabular}

\section{DISCUSSION}

The present study documents that almost all the participants had heard about dengue and mostly were aware that it is caused by the bite of the mosquito. Similar results have been observed in other studies done in India. ${ }^{(1-}$ 13) But in various other studies done by Jogdand KS et al, in south India and Taksande A et al, from central India in which $78.65 \%$ and $76.58 \%$ of respondents knew that dengue fever is transmitted by mosquito. ${ }^{14,15}$ In this study only $2 \%$ of them knew about correct timing of biting habit (night) of dengue spreading mosquitoes, similar result was found in study done by Mohapatra $\mathrm{S}$ et al in Bihar in which $14 \%$ of respondents were aware about biting habit of dengue spreading mosquito. ${ }^{16}$

It was good to see that workers were aware that testing facility for dengue was available in many city laboratories and therefore if they suspected any family member or friend of having dengue, immediate medical help could be sought. Regarding the breeding places of the vector, majority knew that stagnant water is the culprit but despite this knowledge, very few of the workers cleaned their coolers or water containers on alternate days or once a week. Rest of the workers still were less cautious in this aspect. The correct treatment measures for dengue after its diagnosis is important so that a patient does not land into its serious complications. The role of health care worker is important here who should be educating people about the correct management of dengue by camps or lectures. Electronic and print media again can play a vital role in dissipation of such information. Many participants knew that papaya and kiwi are beneficial in dengue. Such beliefs/ rituals which usually no medical basis have but papaya seeds are known to benefit dengue patients. People need to be educated that they should carefully follow the instructions of the registered medical practitioner and not to self-medicate. Many still think that it is always necessary to hospitalize a dengue patient and hence sometimes due to financial constraints they refrain from consulting a doctor. 
The need is to spread awareness that if timely management is done with the help of a doctor, patient can be managed at home and hospitalization can be avoided. Proper care of the patient, adequate bed rest and compliance of doctor's instructions can generally treat the patient of dengue. Most of the respondents were aware of one or the other measures for prevention of dengue like prevention of stagnant water, use of mosquito repellents, wearing full sleeve clothes and regular cleaning of coolers. Also, they were aware that government sprays insecticides to control mosquitoes. Small sample size may have limited our ability to detect associations that were small and moderate in magnitude.

\section{CONCLUSION}

Dengue is prevalent and people are not aware about this disease. There is a need for educating the society about this disease prevention, diagnosis and treatment.

Funding: No funding sources

Conflict of interest: None declared

Ethical approval: The study was approved by the Institutional Ethics Committee

\section{REFERENCES}

1. Mustafa MS, Rasotgi V, Jain S, Gupta V. Discovery of fifth serotype of dengue virus (DENV-5): a new public health dilemma in dengue control. Med J Armed Forces India. 2015;71(1):67-70.

2. Chakravarti A, Arora R, Luxemburger C. Fifty years of dengue in India. Trans R Soc Trop Med Hyg. 2012;106(5):273-82.

3. Ramakrishnan SP, Gelfand HM, Bose PN, Sehgal PN, Mukherjee RN. The epidemic of acute haemorrhagic fever, Calcutta, 1963; epidemiological inquiry. Indian J Med Res. 1964;52:633-50.

4. Chaturvedi UC, Nagar R. Dengue and dengue haemorrhagic fever: Indian perspective. J Biosci. 2008;33(4):429-44.

5. Gubler DJ. Dengue and dengue Hemorrhagic fever. Clin Microbiol Rev. 1998;11(3):480-96.

6. World Health Organization, Special Programme for Research, Training in Tropical Diseases, World Health Organization. Department of Control of Neglected Tropical Diseases, World Health Organization. Epidemic, Pandemic Alert. Dengue: guidelines for diagnosis, treatment, prevention and control. World Health Organization; 2009. Available at: https://www.who.int/tdr/publications/documents/den gue-diagnosis.pdf

7. Guzman MG, Halstead SB, Artsob H, Buchy P, Farrar J, Gubler DJ, et al. Dengue: A continuing global threat. Nat Rev Microbiol. 2010;8(Suppl):S7-16.

8. WHO. Global strategy for dengue prevention and control, 2012-2020. Geneva: WHO Press; 2012. Available https://www.who.int/denguecontrol/9789241504034/ en/

9. Gupta P, Kumar P, Aggarwal OP. Knowledge, attitude and practices related to dengue in rural and slum areas of Delhi after the dengue epidemic of 1996. J Commun Dis. 1998;30(2):107-12.

10. Peters CJ. Infections caused by arthropod and rodent borne viruses. In: Longo DL, eds. Harrison's Principal of Internal Medicine. $18^{\text {th }}$ Ed. New York: Mc GrawHill; 2012: 1164.

11. Matta S, Bhalla S, Singh D, Rasania SK, Singh S. Knowledge, attitude \& practice (KAP) on dengue fever: a hospital based study. Indian J Comm Med. 2006;31(3):185-6.

12. Chinnakali P, Gurnani N, Upadhyay RP, Parmar K, Suri TM, Yadav K. High level of awareness but poor practices regarding dengue fever control: a cross sectional study from North India. N Am J Med Sci. 2012;4(6):278-82.

13. Malhotra V, Kaur P. The community knowledge, attitude and practices regarding dengue fever infield practice area of urban training health centre of Patiala. Int J Res Dev Health. 2014;2(1):19-26.

14. Jogdand KS, Yerpude P. The Community knowledge and practices regarding dengue fever in an urban slum area of south India. Peoples J. 2013;6(1):13-5.

15. Taksande A, Lakhkar B. Knowledge, Attitude and Practice (KAP) of Dengue Fever in the Rural Area of Central India. Shiraz E Med J. 2012;13(4):146-57.

16. Mohapatra S, Aslami AN. Knowledge, attitude and practice regarding dengue fever among general patients of a rural tertiary-care hospital in Sasaram, Bihar. Int $\mathrm{J}$ Community Med Public Health. 2016;3(2):586-91.

Cite this article as: Roshi, Sharma S, Tandon VR, Gupta BM. Assessment of knowledge, attitude and practice about dengue in factory workers of Jammu region, India. Int J Basic Clin Pharmacol 2019;8:1680-4. 